\title{
Key determinants of malnutrition of children under five years of age in Rwanda: Simultaneous measurement of three anthropometric indices
}

\author{
F. Habyarimana ${ }^{1}$, T. Zewotir ${ }^{2}$, and S. Ramroop ${ }^{3}$ \\ School of Mathematics, Statistics and Computer Science \\ University of KwaZulu Natal \\ Correspondence: habyarafaustin@yahoo.fr
}

\begin{abstract}
Malnutrition of children is a serious problem to the public health, most especially in developing countries. Based on Rwanda Demographic and Health Survey Data, the joint model of a multivariate generalized linear mixed model is used to simultaneously identify the determinants of malnutrition of children under five years of age in Rwanda using height-for-age, weight-forage and weight-for-height. Each anthropometric index has been categorized as malnourished (Z-score value $<-2.0$ ) and nourished (Z-score value $\geq-2.0$ ). The study found that the age of the child, gender of the child, birth weights, mother's knowledge of nutrition, birth order, incidence of recent fever, multiple births, education level of the mother, age of the mother at childbirth, body mass index, prevalence of anemia, province, source of drinking water and wealth quintiles are the key determinants of malnutrition of children under five years of age in Rwanda. A positive correlation between stunting and underweight and wasting and underweight was found. Therefore this study suggests that when eradicating malnutrition of children under five years of age, all three types of malnutrition should be corrected. It also suggests strengthening the policy on educating people in planning the number of children born to them
\end{abstract}

Keywords: Stunting, Underweight, Wasting, multivariate, Millennium Development Goals, Joint modelling.

\section{Résumé}

La malnutrition des enfants est un problem grave de santé publique, surtout dans les pays en development. Basé sur les données de l'enquête démographique et de santé au Rwanda, le modèle conjoint d'un multivariée géneralisée de modèle linéaire mixte est utilizé pour identifier simultanément les determinants de la malnutrition des enfants de moins de cinq ans au Rwanda en utilisant la taille-pour-âge (retard de croissance), le poids-pour-âge (insufisance pondérale) et le poids-pour-taille (emaciation). Chaque indice anthropométrique a été classé comme malnourri (Z-score<-2.0) et nourri $(Z$-score $\geq-2.0)$. La recherche a révélé que l'âge de l'enfant, le sexe de l'enfant, le poids de l'enfant à la naissance, la connaissance de la mère sur la nutrition, le rang de naissance de l'enfant, l'incidence de la fièvre récente, les naissance multiples, le niveau d'instruction de la mère, , l'âge de la mère à la naissance, l'indice de masse corporelle de la mere, la prevalence de l'anémie, la province de residence, source d'eau potable et les quintiles de bien-être économique de la famille sont les principaux determinants de la malnutrition des enfants de moins de cinq ans au Rwanda. Une correlation positive entre le retard de criossance et l'insuffisance pondérale et l'émaciation et l'insuffisance pondérale a été trouvé. Par consequent, l'étude suggère que, lorsqu'on eradique la malnutrition des enfants de moins de cinq ans, les trois types de malnutrition doivent être corrigées. II suggère également de renforcer la politique sur l'éducation des gens dans la planification du number d'enfants nés à eux.

Motsclés: Retard de croissance, insuffisance pondérale, émaciation, objectifs de development du millénnaire, la modélisation conjointe. 


\section{Introduction}

Child malnutrition is a serious public health problem which is prevalent mostly in developing countries. Malnutrition has significant health effects on childhood and adulthood development (Takele, 2013; Tathiah et al.,2013; Walker et al., 2007). According to some estimates, malnutrition of children is implicated in over $50 \%$ of deaths in developing countries (Kandala et al., 2001; UNICeF, 1998). Malnutrition of the children can lead to impairment and affects the cognitive capacity in the long run reduces labour productivity in adulthood (Unicef, 1997). The majority of this work is drawn from the research found in Habyarimana (2016).

\section{Literature Review}

Children are more susceptible to malnutrition deficiencies than adults (Kandala et al.,2011; Tharakan and Suchindran, 1999). Malnutrition of children is defined as a clinical sign of nutrient deficiency which manifests as stunting, underweight and wasting. These manifestations can be determined based on clinical signs, biochemical or anthropometric indicators (Group, 1986;Onis, 2000; Zere and Mclntyre, 2003). However, anthropometric indicators are frequently used due to being cost effective and relatively easily available (Folasade, 2000). Biochemical and clinical signs are useful in cases of extreme malnutrition (Onis, 2000; Zere and Mclntyre, 2003).

Frequently used anthropometric indicators to measure malnutrition of children under five years of age (WHO, 1995) are: stunting or insufficient height-for-age representing chronic malnutrition; wasting or insufficient weight-forheight, representing the inadequate food nutrition intake in the period immediately prior to the survey or a recent affliction of illness resulting in weight-loss and the onset of malnutrition; and underweight or insufficient weight-for-age. This means that a child may be underweight if he/she is either wasted or stunted, or both. Stunting in the community has been associated with poor socio-economic conditions Skoufias (1998).

If the measurements of anthropometric indicators are consistently taken over a defined period, they can offer indicative information on the change in population health status and provide a timely warning associated with the food supply of a particular region. But if the aim of the study is to get a quick snapshot of a community in order to investigate the magnitude of the problem, the measurements of wasting would offer substantial information. But, if the aim is to get information for determining on what types of programs are required in the target region, the study can include all three indices of anthropometric measurements (Setboonsarng, 2005). These three anthropometric indicators are measured based on Z-scores values for stunting, wasting and underweight and are determined by the following formula:

$$
Z_{i}=\frac{A I_{i}-\mu}{\sigma}
$$

where $A I_{i}$ is the child (individual) anthropometric indicator, $\mu$ and $\sigma$ are the median and standard deviation of the reference population (child) respectively. Note that the higher the values of the Z-score for any of anthropometric variables, the better the nutrition status of the child and the lower the values of the Z-score the greater the level of malnutrition of the child. One of the targets adopted by the international community at the millennium summit as a part of its Millennium Development Goals is to reduce malnutrition by half (AbouZahr and Wardlaw, 2001; Wagstaff, 2004).

In developing countries in general and in Rwanda in particular, malnutrition poses a serious threat to the health system. The prevalence of stunting among children under age five is approximately $44 \%$, while $11 \%$ are underweight and $3 \%$ are wasted (NISR et al., 2012). However, the Rwandan government actively engages in solution generation for this problem (NISR et al., 2012).

In literature, many authors proposed various statistical models, in the study of determinants of child under five years of age (Bassolé, 2007; Das and Rahman, 2011; Habyarimana et al., 2014; Islam et al., 2013; Kandala et al., 2011; Khatab, 2010; Matanda et al., 2014; Tharakan and Suchindran, 1999). In all these studies the indicators of underweight, stunting or wasting were considered separately. But, a child may be well nourished or stunted, or underweight, or wasted, or wasted and underweight at the same time, or underweight and stunted at the same time). A separate model cannot identify the possible association between these three outcomes. Therefore, the main objective of current study is to utilize a joint model for a multivariate generalized linear mixed model to simultaneously identify the key determinants of stunting, wasting and underweight and to find out the possible correlation among them. The joint modelling has a substantial advantages compared to separate modelling. These include better control of the Type I error rates, possible gains in efficiency in the parameter estimates 
and the capacity for answering the multivariate question (Gueorguieva, 2001; Verbeke, 2005). There is no study in the literature using a joint model for multivariate generalized linear mixed model in order to simultaneously find the key determinants of underweight, stunting and wasting of children under age five in Rwanda. The variables of interest considered in the analysis. The sampling in this survey used a two-stage stratified method; where in the first stage 492 villages, known also as primary sampling units were selected based on the probability proportional to the village size. The survey considered 2009 and 10531 urban and rural households respectively. In the second stage, systematic sampling technique was utilized. The survey constitutes the collection of data from female aged 15-49 years and 4,356 children under five years of age, on height in centimeters, weight in kilograms and age in months, birth weights, incidence of anemia, gender of the child, multiple births, province, mothers' body mass index, wealth quintiles, birth order, education of the parents, nutritional knowledge, residence, types of housing and toilet, incidence of illness for instance cold, cough, diarrhea, and others in the two weeks preceding the survey, marital status, and caretaker of the child, incidence of breastfeeding, and feeding index. These are considered in general as explanatory variables on malnutrition. The current study considered child's characteristic variables, mother's characteristic variables and household's characteristic variables. But for the sake of brevity, the results only report significant predictor variables. The RDHS (2010) data provides the information on weight-for-age, height-for-age and weight-for-height. In this study, the child's nutrition status has been classified into nourished (Z-score value $\geq-2.0$ ) and malnourished (Z-score value $<-2.0)$, which resulted in a binary response variable.

\section{Model overview}

There are many studies in literature using joint modeling (Guo and Carlin, 2004; Tsiatis and Davidian, 2004; Verbeke, 2005; Verbeke et al., 2014), some of them used two response variables (one continuous and the other, binary) and others used a higher dimension joint model but in the current study three binary response variables are considered.

Consider the response vector for $j^{\text {th }}$ subject as $Y_{j}=\left(Y^{\prime}{ }_{j 1}, Y_{j 2}^{\prime}, Y_{j 3}^{\prime}\right)^{\prime}, \quad$ where $\quad Y_{j 1}^{\prime}=$ $\left(y_{j 11}, y_{j 12}, \ldots, y_{j 1 n_{j 1}}\right), Y_{j 2}^{\prime}=\left(y_{j 21}, j, \ldots, y_{j 2 n_{j 1}}\right)$ and $Y_{j 3}^{\prime}=\left(y_{j 31}, y_{j 32}, \ldots, y_{j 3 n_{j 1}}\right)$ and these are current study are described in the next subsection (source of data).

\section{Data and Methods \\ The data}

The current study used the data from Rwanda Demographic Health Survey (RDHS, 2010) for repeated measurements of the first, second and third response variables. It is assumed that $y_{i 1 j}, \quad i=1,2, \ldots, n_{j 1}$ is conditional independent given $b_{j 1}$ with the density function $f_{1}($.$) in the exponential family, y_{j 2 i}, j=$ $1,2, \ldots, n_{j 2}$, are conditional independent given $b_{i 2}$ with the density function $f_{2}($.$) in the$ exponential family and $y_{j 3 i}, i=1,2, \ldots, n_{j 3}$, are conditional independent given $b_{j 3}$ with the density function $f_{3}($.$) in the exponential$ family. $Y_{j 1}, Y_{j 2}$ and $Y_{j 3}$ are also conditionally independent given $b_{j}=\left(b_{j 1}^{\prime}, b_{j 2}^{\prime}, b_{j 3}^{\prime}\right)^{\prime}$ and the response on different subjects are independent. The conditional means of $y_{j 1 i}, y_{j 2 i}$ and $y_{j 3 i}$ are represented as $\mu_{j 1 i}, \mu_{j 2 i}$ and $\mu_{j 3 i}$ respectively, where $\mu_{j 1}=$ $\left(\mu_{j 11}, \mu_{j 12}, \ldots, \mu_{j 1 n_{j 1}}\right)^{\prime}$

$\mu_{j 2}=\left(\mu_{j 21}, \mu_{j 22}, \ldots, \mu_{j 2 n_{j 2}}\right)^{\prime} \quad$ and $\quad \mu_{j 3}=$ $\left(\mu_{j 31}, \mu_{j 32}, \ldots, \mu_{j 3 n_{j 3}}\right)^{\prime}$. The mixed model specification is assumed to be

(2)

$$
\begin{aligned}
& g_{1}\left(\mu_{j 1}\right)=X_{j 1} \beta_{1}+Z_{j 1} b_{1} \\
& g_{2}\left(\mu_{j 2}\right)=X_{j 2} \beta_{2}+Z_{j 2} b_{2} \\
& g_{3}\left(\mu_{j 3}\right)=X_{j 3} \beta_{3}+Z_{j 3} b_{3}
\end{aligned}
$$

(3)

where $\beta_{1}, \beta_{2}$ and $\beta_{3}$ are $\left(p_{1} \times 1\right),\left(p_{2} \times 1\right)$ and $\left(p_{3} \times 1\right)$ dimensional unknown parameter vectors, $X_{j 1}, X_{j 2}$ and $X_{j 3}$ are $\left(n_{j 1} \times p_{1}\right)$, $\left(n_{j 2} \times p_{2}\right), \quad$ and $\left(n_{j 3} \times p_{3}\right)$ dimensional matrices for the fixed effects, $Z_{j 1}, Z_{j 2}$ and $Z_{j 3}$ are $\left(n_{j 1} \times q_{1}\right), \quad\left(n_{j 2} \times q_{2}\right)$, and $\left(n_{j 3} \times q_{3}\right)$ dimensional design matrices for the random effects

$$
\begin{gathered}
b_{j}=\left(\begin{array}{l}
b_{j 1} \\
b_{j 2} \\
b_{j 3}
\end{array}\right) \sim \text { i. i. d. } \operatorname{MVN}(0, \Sigma)= \\
\operatorname{MVN}\left(\left[\begin{array}{l}
0 \\
0 \\
0
\end{array}\right],\left[\begin{array}{lll}
\sum_{11} & \sum_{12} & \sum_{13} \\
\sum_{12}^{\prime} & \sum_{22} & \sum_{23} \\
\sum_{13}^{\prime} & \Sigma_{23}^{\prime} & \sum_{33}
\end{array}\right]\right)(5)
\end{gathered}
$$

where $\sum, \sum_{11}, \sum_{22}$ and $\sum_{33}$ are unknown positive definite matrices. If $\sum_{12}=\sum_{13}=\sum_{23}=$ 0 then the model (5) reduces to three separate generalized linear mixed models. 


\section{Parameter estimation}

There exist various procedures for estimating the parameters in joint modeling. These include for instance numerical approximation such as Gaussian quadrature or Laplace approximation or approximation of the data by the pseudo-likelihood. The pseudo-likelihood approach is used when estimating the parameter in marginal model and random effect without or with correlation, while Results and interpretation

\begin{tabular}{|c|c|c|c|}
\hline Variable indicator & Levels & Number observed & $\%$ \\
\hline \multirow[t]{3}{*}{ Child age } & $0-11$ moths & 786 & 19.0 \\
\hline & $12-22$ months & 794 & 19.2 \\
\hline & 23 -59months & 2553 & 61.8 \\
\hline \multirow[t]{4}{*}{ Birth order } & $1^{\mathrm{st}}$ & 2253 & 25.0 \\
\hline & $2-3$ & 3078 & 34.2 \\
\hline & $4-5$ & 1940 & 21.6 \\
\hline & 6 and more & 1731 & 19.2 \\
\hline \multirow[t]{2}{*}{ Gender of child } & Female & 4416 & 49.1 \\
\hline & Male & 4586 & 50.9 \\
\hline \multirow[t]{2}{*}{ Birth weight } & $<2500 \mathrm{~g}$ & 379 & 4.2 \\
\hline & $\geq 2500 \mathrm{~g}$ & 8599 & 95.8 \\
\hline \multirow[t]{3}{*}{ Multiple birth } & Singleton & 8734 & 97.0 \\
\hline & $1^{\text {st }}($ twin $)$ & 134 & 1.5 \\
\hline & $2^{\text {nd }}$ and more & 134 & 1.5 \\
\hline \multirow[t]{2}{*}{ Incidence of fever } & Yes & 2332 & 15.8 \\
\hline & No & 7085 & 84.2 \\
\hline \multirow[t]{2}{*}{ Mother's age at the birth } & $<21$ & 383 & 4.5 \\
\hline & $\geq 21$ & 8101 & 95.5 \\
\hline \multirow[t]{3}{*}{ Mother's education } & No education & 1702 & 18.9 \\
\hline & Primary & 6451 & 71.7 \\
\hline & Secondary and higher & 849 & 9.4 \\
\hline \multirow{2}{*}{$\begin{array}{l}\text { Mother's knowledge on } \\
\text { nutrition }\end{array}$} & Yes & 4443 & 64.0 \\
\hline & No & 2497 & 36.0 \\
\hline \multirow[t]{2}{*}{ Incidence of anemia } & Anemic & 1428 & 38.3 \\
\hline & No anemic & 2305 & 61.7 \\
\hline \multirow[t]{2}{*}{ Body mass index(BMI) } & $<18.5$ & 205 & 4.5 \\
\hline & $\geq 18.5$ & 4326 & 95.5 \\
\hline \multirow[t]{2}{*}{ Source of drinking water } & Piped into dwelling & 366 & 4.1 \\
\hline & Public tap & 2382 & 26.7 \\
\hline
\end{tabular}

quadrature or Laplace approximations is only used when estimating the parameters in conditional independent random effect model. SAS procedure PROC GLIMMIX (SAS 9.3) can be utilized when estimating parameters in the case of pseudo-likelihood approaches whilst the NLMIXED procedure can be used when estimating parameter using Laplace approximation or Gaussian quadrature. In the current study PROC GLIMMIX (SAS 9.3) is used.

\section{Table 1. Distribution of frequencies of Explanatory variables used in the analysis}


African Population Studies Vol. 30, No. 2, 2016

\begin{tabular}{lccc}
\hline & Protected spring/well & 3425 & 38.5 \\
& Other sources of water & 2734 & 30.7 \\
\hline Wealth index & Poor & 3533 & 39.8 \\
& Middle & 3568 & 40.2 \\
& Rich & 1772 & 20.0 \\
\hline
\end{tabular}


Table 1 shows the observed number and percentage of explanatory variables used in the analysis.

The child age was categorized in three groups as follows: infant (0-11 months), 12 to 22 months and 23 to 59 months. From Table 1 , we observe that $19.0 \%$ of all observed children was infant, $19.2 \%$ of all observed children was aged between 12 and 22 months; whereas children aged from 23 to 59 months were $61.8 \%$ of all observed children. The birth order was classified as follows: First, second and third, fourth and fifth and finally a sixth or later born. It was observed from the Table1 that $25.0 \%, 34.2 \%, 21.6 \%$ and $19.2 \%$ were respectively first, second and third, fourth and fifth and finally sixth or later born. The survey considered almost the equal number of female and male children, where $49.1 \%$ were female and $50.9 \%$ male. It can be observed from the same table that most of sampled children have the birth weight $\geq 2500 \mathrm{~g}$ (95.8\%). Most of children observed were born singleton $(97.0 \%)$. The incident of fever was also considered. It is observed from the table that $15.2 \%$ of all children observed had fever before two weeks prior to the survey.

It is observed from Table 1 that $95.5 \%$ of all mothers observed in Rwanda give birth at age $\geq 21$. From the same table, it is observed that most mothers had primary education (71.7\%), $18.9 \%$ had no education and $9.4 \%$ had at least higher education level. The anemic mothers were $38.3 \%$, whereas no anemic were $61.7 \%$ of all observed mothers. $4.5 \%$ of all observed mothers had body mass index $<18.5$ and $95.5 \%$ had $\mathrm{BMI} \geq 18.5$. The mother's knowledge on nutrition also was considered and it was observed that $64.0 \%$ of all observed mothers had knowledge on nutrition.

Most of households modally observed use water from protected spring or well (38.5\%) and only $4.1 \%$ use water piped into dwelling. We also note that $39.8 \%$ of all observed households were poor, $40.2 \%$ were in middle income and $20.0 \%$ were rich. The study also considered the province

of residence of the family of the child. It was observed from Table 1 that $24.7 \%, 15.3 \%$, $24.1 \%, 24.9 \%$ and $11.0 \%$ of all observed children are respectively from Eastern, Northern, Western, Southern province and Kigali (capital city).

In Table 3 it is noted that the variable found to be at least significant at one of the three anthropometric indicators is thus considered as a determinant of malnutrition and is made mentioned of in our interpretation. From Table 4 a strong positive correlation is seen between the variables: underweight and wasting and then the pair, underweight and stunting. This does not come as surprise since it is an established scientific fact that underweight is known to be the composite index between stunting and wasting. This finding within the ambit of the current scientific setting is uniform with the findings of other researchers as well (Blössner et al., 2006; Nguefack-Tsague and Dapi, 2011; Nguefack-Tsague et al., 2013).

Stunting: The following variables viz. child's age, birth order, mother's age at childbirth, mother's education, gender of the child, birth weight, province, mother's knowledge of nutrition and wealth index are the determinants of stunting (low height-for-age). The summary of the results is reported in Table 3 . The research reveals that the age of the child significantly affects height-for-age. It is observed from the results that at age 12 to 23 months the prevalence of stunting is higher $(\mathrm{OR}=3.428$, $\mathrm{p}$-value <.0001) compared to infant (0-11 moths). It is also noted that the birth order significantly affects the height-forage of the child. The finding show that the sixth born children and consequently those children born thereafter are more likely to be stunted $\quad(O R=1.652, \quad p$-value $=0.0002)$ compared to first born children.

The variable of mother's age at childbirth significantly affects the height-for-age of the child (Table 3). A child born to mother aged younger than 21 years old is 1.737 ( $p$ value $=0.0096$ ) times more likely to be in stunting status compared to a child born to mother older than 21 years of age. This might possible hint at maternal, emotional and educational maturity of the mother in being able to provide sustenance for the child.

The role of education cannot be overemphasized as a determinant that can alleviate malnutrition. The findings highlighted in that a mother's level of education also significantly influences the height-for-age of the child. The results reveal that the z-score of height-for-age increases with increasing education levels of the mother (Table 3). Consequently it is submitted that stunting and the mother's level of education are inversely proportional to each other. Furthermore, a child born to a mother with a primary or a secondary or higher education level is 0.0518 ( $p$-value <.0001) or 0.0406 ( $p$-value <.0001) 
times less likely to be underweight than a child born to a mother with no education, respectively. The gender of the child significantly affects his/her height-for-age (Table 3). The risk of having a low height-forage $z$-score score is 0.639 ( $p$-value <.0001) times lower among female children than male children.

The results show that the child birth weight also significantly influences stunting. A child born with low weight $(<2500 \mathrm{~g})$ has $78.6 \%$ odds of being stunted $(O R=1.786, p$-value $=0.0115$ ) compared to a child born with a higher weight.

Province of birth is a significant indicator of the height-for-age of the child (Table 3 ). The risk of having a lower height-for-age z-score of children born in Western province is $54.4 \%$ (OR=1.544, $\quad \mathrm{p}$-value $=0.0409)$ compared to children born Eastern province. Similarly, a child born in Southern province has $40.3 \%$ odds of having lower height-for-age z-score $(\mathrm{OR}=1.403, \mathrm{p}$-value $=0.023)$ compared to a child born in Eastern province.

We find that the mother's knowledge of nutrition is also a significant predictor for the height-for-age of the child (Table 3). The odds of a child born to a mother without knowledge of nutrition is 1.296 ( $p$-value $=0.0047$ ) times more likely to be stunted than that of a child born to a mother with some knowledge of nutrition.

Finally it is noted that the wealth index significantly affects the height-for-age of the child (Table 3), since the trend that as stunting increases the wealth index decreases. This is evidence of an inverse relationship. Further it is evident that a child born into a poor family is 1.543 ( $p$-value $=0.0079$ ) times more likely to be stunted than a child born into a rich family.

Wasting: The salient results of the current research reveal that a child's age, birth order, the birth weight of the child, wealth index, body mass index of the mother, recent incidence of fever, and source of drinking water all significantly influence the height-for-weight of the child (Table 3 ).

Age is a significant predictor of the heightfor-weight of the child (Table 3). A child aged between 12 to 23 months has $59.4 \%$ odds of having wasting ( $\mathrm{OR}=0.406$, $\mathrm{p}$-value $=0.0028$ ) compared to an infant (aged 0 to 11 months). A similar trend is seen in that a child aged between 23 and 59 months has $82.6 \%$ odds of being wasted $(\mathrm{OR}=1.826$, $p$-value $=0.0442)$ compared to an infant. Therefore, it is noted from these results that prevalence of wasting increases with increasing age of the child (12 to 59 months).

The birth order is a significant predictor of child's height-for-weight (Table 3 ). It is noted that the prevalence of wasting is higher among sixth (or later) born children (OR=2.651, $\mathrm{p}$ value $=0.0311$ ) compared to first born children.

Furthermore, birth weight is also a significant factor for the height-for-weight of the child (Table 3 ). The odds of a child born with lower weight $(<2500 \mathrm{~g})$ is 4.05 ( $p$ value $=0.0018$ ) times more likely to be wasted than a child born with a higher weight $(\geq 2500 \mathrm{~g})$. Hence the birth weight of the child is of tantamount consequence in affecting the wasting of a child.

The wealth index is also a significant predictor of the height-for-weight of the child (Table 3). It is noted that the prevalence of wasting is higher among children born into a poor family $(\mathrm{OR}=3.680, \quad \mathrm{p}$-value $=0.0194)$ compared to children born into a rich family.

The body mass index of the mother also significantly affects wasting (Table 3 ). We find that a child born to an underweight mother $(\mathrm{BMI}<18.5$ ) is 3.222 ( $p$-value=0.0052) times more likely to be wasted than a child born to a normal or obese mother (BMI $\geq 18.5)$. Thus the relationship between the weight of the mother and nutrition status of the child is highlighted.

Fever is also a significant predictor of child's height-for-weight (Table 3). It is noted from the results that wasting is higher among children reported to have had a fever in the two weeks prior to the survey $(\mathrm{OR}=1.763$, $\mathrm{p}$ value $=0.0427$ ) compared to children who did not have a fever during the two weeks preceding the survey.

The source of drinking water significantly influences the nutritional status of the child (weight-for-height) (Table 3). A child born into a family where water piped is delivered into their dwelling or yard has $87.0 \%$ lower odds of having wasting $(\mathrm{OR}=0.130$, $\mathrm{p}$-value $=0.0045)$ compared to a child born into a family where water comes from other sources (not piped in dwelling/yard, public tap and protected spring or well). Similarly, a child born into a family where they use water from a public tap has $74.1 \%$ lower odds of having wasting (OR=0.259, p-value $=0.0007$ ) than the child from a family where they use water from other sources (not piped in dwelling/yard, not from protected spring or well). The issue of access to water is emphasized in that, water that is not piped in dwelling/ yard, water that is not from public tape or which is not from a 
protected spring or well may be associated with childhood diseases such diarrhea among others. Potable water is very important in order to fight wasting and other related consequences.

Underweight: The results pertaining to the condition of underweight show that the child's age, birth order, education level of the mother, gender of the child, birth weight of the child, mother's knowledge of nutrition, multiple births, anemia and BMI of the mother are the key determinants of malnutrition of the child (Table 3). These variables are consistent with those of stunting and wasting as discussed in previous sections.

Underweight is significantly lower among children aged 23 months or more $(\mathrm{OR}=0.798$, $\mathrm{p}$-value $=0.0411$ ) than infant Table 3.

The birth order also significantly influences the weight-for-age of the child such that underweight increases with increasing the birth order (Table 3). It is evident that a second or third born child is 1.296 ( $p$-value $=0.0473$ ) times more at risk of being underweight than first born. Similarly, underweight is higher among fourth or fifth born child (OR=1.346, $p$ value $=0.0341$ ) compared to a first born. Furthermore, a sixth or later born child has $34.6 \%$ higher odds of having underweight (OR=2.948, $p$-value<.0001) compared to first born.

The educational level of the mother once again significantly affects the weight-for-age of the child. The inverse relationship is seen in that the extent to which a child is underweight decreases with an increase in the mother's level of education (Table 3). Furthermore, a child born to a mother with primary, secondary or higher education level is 0.097 ( $p$-value $<.0001$ ) or 0.058 ( $p$-value <.0001) less likely to have an underweight status than a child born to a mother with no education, respectively.

The gender of the child is a significant predictor of the weight-for-age of the child (Table 3 ). It is observed from the results that the prevalence of underweight is lower in female children (OR=0.617, $\mathrm{p}$-value <.0001) compared to male children.

The issue of birth weight is also highlighted because birth weight significantly influences the weight-for-age of the child, as well (Table 3 ). It is evident that a child born with low birth weight (less than $2500 \mathrm{~g}$ ) has $16 \%$ higher odds of having underweight $(\mathrm{OR}=3.16$, $p$-value $<.0001)$ than a child born with a higher weight.

The results show that the mother's knowledge of nutrition significantly influences the weight-for-age of the child (Table 3). The odds are interpreted as follows: a child born to a mother without knowledge of nutrition is 1.416 ( $p$-value $=0.0015)$ times more likely to be underweight than a child born to a mother with some knowledge of nutrition.

Multiple births are a significant predictor of the weight-for-age of the child (Table 3), where the extent of underweight increases with increasing the incident of multiple birth. A directly proportional relationship is thus noted. Furthermore, it is observed from the results that underweight is higher among children born as the first multiple $(\mathrm{OR}=3.842, p$ value $=0.0002$ ) than singleton children.

The incidence of anemia also significantly affects the weight-for-age of the child. It is evident from the results that a children born to a non-anemic mother are 0.691 less likely to be underweight compared to children born to an anemic mother ( $p$-value $=0.0002)$. As stated earlier, the BMI of the mother significantly influences the weight-for-age of the child (Table 3). It was noted from the results that underweight is more frequent in children born to underweight mother $(\mathrm{OR}=3.096$, $p$ value $<.0001)$ compared to children born to a normal weight, overweight or obese mother (BMI $\geq 18.5$ ).

Fever also significantly influences children's weight-for-age (Table 3 ). It is seen that underweight is higher among children who had a fever in the two weeks preceding the survey are $(\mathrm{OR}=1.667$, $\mathrm{p}$-value <.0001) compared to children who did not have a fever during the same time frame. 
Table 2. Type 3 tests of fixed effects

\begin{tabular}{lllll}
\hline Explanatory variables & Num. Df & Den.Df & F value & P-value \\
\hline Child's age & 6 & 9759 & 19.66 & $<.0001$ \\
\hline Birth order & 9 & 9759 & 7.74 & $<.0001$ \\
\hline Gender of the child & 3 & 9773 & 18.14 & $<.0001$ \\
\hline Birth weight & 3 & 9759 & 14.54 & $<.0001$ \\
\hline Multiple birth & 6 & 9759 & 3.13 & 0.0046 \\
\hline Mother's age at childbirth & 3 & 9773 & 2.4 & 0.0663 \\
\hline Incidence of fever in previous 2 weeks & 3 & 9759 & 7.27 & $<.0001$ \\
\hline Incidence of Anemia & 3 & 9759 & 5.88 & 0.0005 \\
\hline Body Mass Index & 3 & 9759 & 13.24 & $<.0001$ \\
\hline Mother's education level & 6 & 9773 & 10.24 & $<.0001$ \\
\hline Knowledge of nutrition & 3 & 9759 & 5.71 & 0.0007 \\
\hline Wealth index & 6 & 9759 & 2.31 & 0.0311 \\
\hline Source of drinking water & 9 & 9773 & 2.38 & 0.0108 \\
\hline Province & 12 & 9759 & 2.4 & 0.0043 \\
\hline
\end{tabular}


Table 3.Parameter estimates for a joint marginal model for anthropometric measurements of malnutrition

\begin{tabular}{|c|c|c|c|c|c|c|c|c|c|}
\hline & Wasting & & & Underwei & ight & & Stunting & & \\
\hline $\begin{array}{l}\text { Indicator } \\
\text { variable }\end{array}$ & Estimate & SE & $\begin{array}{l}p- \\
\text { value }\end{array}$ & Estimate & SE & $\begin{array}{l}p- \\
\text { value }\end{array}$ & Estimate & SE & $\begin{array}{l}p- \\
\text { value }\end{array}$ \\
\hline Intercept & -1.232 & 0.686 & 0.0726 & 3.186 & 2.054 & 0.121 & 1.181 & 0.971 & 0.224 \\
\hline \multicolumn{10}{|c|}{ Child's age (ref $=0-11$ months) } \\
\hline $\begin{array}{l}12-23 \\
\text { months }\end{array}$ & -0.901 & 0.3017 & 0.0028 & 0.004 & 0.1583 & 0.9799 & 1.232 & 0.1529 & $<.0001$ \\
\hline $23+$ months & 0.602 & 0.299 & 0.0442 & -0.225 & 0.1099 & 0.0411 & -0.145 & 0.0960 & 0.1302 \\
\hline \multicolumn{10}{|c|}{ Birth order (ref=first) } \\
\hline 2-3orders & 0.095 & 0.3533 & 0.7882 & 0.259 & 0.1307 & 0.0473 & 0.142 & 0.1214 & 0.2424 \\
\hline $4-5$ orders & -0.380 & 0.362 & 0.2944 & 0.297 & 0.14 & 0.0341 & 0.130 & 0.1315 & 0.3236 \\
\hline $6+$ orders & 0.975 & 0.4521 & 0.0311 & 1.081 & 0.1659 & $<.0001$ & 0.5029 & 0.137 & 0.0002 \\
\hline \multicolumn{10}{|c|}{ Mother's age (ref $=\geq 21$ years) } \\
\hline$<21$ years & 0.379 & 0.673 & 0.573 & 0.131 & 0.2641 & 0.6209 & 0.552 & 0.2129 & 0.0096 \\
\hline \multicolumn{10}{|c|}{ Mother's education (ref=no education) } \\
\hline Primary & -0.547 & 0.4822 & 0.2566 & -2.334 & 0.3685 & $<.0001$ & -0.658 & 0.1857 & 0.0004 \\
\hline $\begin{array}{l}\text { Secondary } \\
\text { and Higher }\end{array}$ & -0.3232 & 0.552 & 0.5582 & -2.829 & 0.3816 & $<.0001$ & -0.902 & 0.2064 & $<.0001$ \\
\hline
\end{tabular}

Gender of the child (ref=male)

$\begin{array}{llllllllll}\text { Female } & -0.3342 & 0.2452 & 0.1633 & -0.482 & 0.0943 & <.0001 & -0.447 & 0.0833 & <.0001\end{array}$

Birth weight $($ ref $=\geq 2500 \mathrm{~g}$ )

\begin{tabular}{llllllllll}
$<2500 \mathrm{~g}$ & 1.4 & 0.4481 & 0.0018 & 1.151 & 0.2095 & $<.0001$ & 0.580 & 0.2294 & 0.0115 \\
\hline
\end{tabular}

Province (ref=Eastern)

\begin{tabular}{llllllllll} 
Kigali & -0.259 & 0.4973 & 0.6028 & 0.2905 & 0.3128 & 0.3531 & -0.159 & 0.212 & 0.3641 \\
\hline South & 0.246 & 0.3746 & 0.5110 & 0.351 & 0.222 & 0.1137 & 0.339 & 0.1491 & 0.023 \\
\hline West & 0.65 & 0.3756 & 0.836 & 0.0493 & 0.2137 & 0.8176 & 0.435 & 0.7142 & 0.0409 \\
\hline North & 0.924 & 0.51 & 0.0701 & 0.414 & 0.2485 & 0.0954 & -0.150 & 0.1618 & 0.3549 \\
\hline
\end{tabular}

Knowledge of nutrition (ref=no)

\begin{tabular}{llllllllll} 
Yes & -0.141 & 0.2543 & 0.58 & 0.348 & 0.1096 & 0.0015 & 0.259 & 0.0916 & 0.0047 \\
\hline
\end{tabular}

Wealth index (ref=rich)

\begin{tabular}{llllllllll} 
Middle & 0.562 & 0.3548 & 0.1129 & 0.144 & 0.1335 & 0.2821 & 0.194 & 0.1105 & 0.0784 \\
\hline Poor & 1.303 & 0.5574 & 0.0194 & 0.228 & 0.2056 & 0.2681 & 0.434 & 0.1636 & 0.0079 \\
\hline
\end{tabular}

Multiple birth (ref=singleton)

\begin{tabular}{llllllllll} 
First multiple & 0.027 & 1.0951 & 0.9804 & 1.346 & 0.364 & 0.0002 & 0.409 & 0.4299 & 0.3413 \\
\hline
\end{tabular}

\begin{tabular}{lllllllllll} 
Second & 0.043 & 1.3326 & 0.9743 & 0.445 & 0.4542 & 0.3272 & 0.138 & 0.5582 & 0.8046 \\
\hline
\end{tabular}


multiple and

more

Incidence of anemia (ref=non-anemic)

\begin{tabular}{|c|c|c|c|c|c|c|c|c|c|}
\hline Anemic & -0.494 & 0.2591 & 0.0568 & -0.370 & 0.0992 & 0.0002 & -0.093 & 0.0882 & 0.2922 \\
\hline \multicolumn{10}{|c|}{ BMI $\quad(r e f=B M I \geq 18.5)$} \\
\hline $\mathrm{BMI}<18.5$ & 1.117 & 0.3993 & 0.0052 & 1.130 & 0.1914 & $<.0001$ & 0.131 & 0.1961 & 0.5028 \\
\hline \multicolumn{10}{|c|}{ Incidence of Fever (ref=no) } \\
\hline Had fever & 0.567 & 0.2795 & 0.0427 & 0.511 & 0.119 & $<.0001$ & 0.010 & 0.1134 & 0.9273 \\
\hline \multicolumn{10}{|c|}{ Source of drinking water (ref=other source) } \\
\hline $\begin{array}{l}\text { Piped into } \\
\text { dwelling/yard }\end{array}$ & -2.041 & 0.718 & 0.0045 & -0.157 & 0.4249 & 0.7115 & 0.436 & 0.3186 & 0.1714 \\
\hline Public tap & -1.352 & 0.4005 & 0.0007 & -0.288 & 0.1588 & 0.0699 & -0.019 & 0.1288 & 0.8802 \\
\hline $\begin{array}{l}\text { Protected } \\
\text { spring/well }\end{array}$ & -0.462 & 0.3185 & 0.1472 & 0.081 & 0.1246 & 0.514 & -0.010 & 0.1038 & 0.336 \\
\hline
\end{tabular}

Table 4.Variance Components

\begin{tabular}{llll}
\hline Label & Estimate & S.E. & P-Value \\
\hline Variance (Stunting) & 0.316 & 0.0728 & $<.0001$ \\
\hline Variance (Wasting) & 0.807 & 0.364 & 0.0133 \\
\hline Variance (Underweight) & 1.392 & 0.178 & $<.0001$ \\
\hline Correlation between stunting and underweight & 0.966 & 0.095 & $<.0001$ \\
\hline Correlation between wasting and underweight & 0.990 & 0.178 & $<.0001$ \\
\hline Correlation between wasting and stunting & 0.0676 & 0.267 & 0.8004 \\
\hline
\end{tabular}

\section{Discussion}

The joint model is advantageous in that the three response variables (underweight, stunting and wasting) is used simultaneously combined with the fact that as the correlation between underweight and wasting and between underweight and stunting is significant. However, if the correlation was not significant, it would have sufficed to use a GLMM. In previous sections the specific advantages of the joint model was given and is not repeated here but is noted. This study measured the simultaneous determinants of wasting, underweight and stunting, this alludes the fact that increasing height-for-age and height-for-weight increases the weight-for-height. The finding that decreasing height-for-age and height-for-weight also decreases the weight-for-age, which is in line with Nguefack-Tsague and Dapi (2011). In other words, reducing stunting has a positive effect of reducing underweight. In other words, reducing stunting has a positive effect of reducing underweight.

\section{Conclusion}

The current study made use of a joint multivariate generalized linear mixed model to identify simultaneously the key determinants of malnutrition of the child under age five in Rwanda using underweight, wasting and stunting. The most salient findings within the ambit of the study revealed that that the age of the child, gender of the child, birth weight, birth order, incidence of fever, mother's education level, mother's age at childbirth, BMI of the mother, incidence of anemia, knowledge of nutrition by mother, province, source of drinking water, occurrence of multiple births and wealth index of the household are the key determinants 
of malnutrition of children under five years in Rwanda.

This research also revealed that stunting and underweight are lower in female children than male children. This result is consistent with the findings of other studies (Habyarimana et al., 2014; Kandala et al., 2011). It also evident that the nutrition status of the mother influences the nutrition status of the child, where an underweight mother is more likely to deliver a wasted or underweight child, a finding which is in line with Das and Rahman (2011). The mother's knowledge of nutrition is a fundamentally important factor in relation to the nutrition of the child. It is essential to indicate that variables such as birth weight of the child and birth order significantly affect all three anthropometric indices. It was also evident that malnutrition decreases with an increase in the mother's level of education, especially in the case of stunting and underweight. These results are consistent with those of other studies (Das \& Rahman, 2011; Habyarimana et al., 2014; Kandala et al., 2011).

\section{Recommendation}

Improving the access to potable water may help to reduce wasting and sensitizing the population to the importance of nutrition may reduce stunting and underweight.

Improving the education level of the women will lead to enhance in maternal health outcomes, consequently improve the health of their children.

Women aged less than 21 years old should be sensitized that early child bearing is associated with childhood stunting.

A good child care and health literacy of the women will substantially reduce not only stunting but also underweight and wasting of the child.

The sensitizing and education should be in the form workshops, pamphlets, mobile clinics disseminating appropriate information on malnutrition and visits by malnutrition experts and health workers.

Strengthening the policy on educating people in planning the number of children born to them may improve the children nutrition status. For future research it is important to highlight that DHS data is cross-sectional, it would be better to carry out a longitudinal study and use a joint model that could include spatial variability.

\section{Acknowledgements}

The authors acknowledge the National Institute of Statistics of Rwanda (NISR) [Rwanda], the Ministry of Health (MOH) [Rwanda], ICF
International for data, Rwanda Education Board (REB) and University of Rwanda-College of Education (UR-CE) for financial support.

\section{References}

AbouZahr, C. and Wardlaw, T. 2001. "Maternal mortality at the end of a decade: signs of progress?" Bulletin of the World Health Organization, 79(6), 561-573.

Bassolé, L. 2007. Child malnutrition in Senegal: does access to public infrastructure really matter? A quantile regression analysis. Paper presented at the 2 nd african economic Conference, Addis Ababa, november.

Blössner, M., de Onis, M. and Uauy, R. 2006. "Estimating stunting from underweight survey data". J Hum Ecol, 14, 145-152.

Das, S. and Rahman, R. M. 2011. "Application of ordinal logistic regression analysis in determining risk factors of child malnutrition in Bangladesh". Nutrition journal, 10(1), 124.

Folasade, I. B. 2000. "Environmental factors, situation of women and child mortality in southwestern Nigeria". Social Science \& Medicine, 51(10), 1473-1489.

Group, W. W. 1986. Use and interpretation of anthropometric indicators of nutritional status. Bulletin of the World Health Organization, 64(6), 929-941.

Gueorguieva, R. 2001. "A multivariate generalized linear mixed model for joint modelling of clustered outcomes in the exponential family". Statistical Modelling, 1(3), 177-193.

Guo, X. and Carlin, B. P. 2004. "Separate and joint modeling of longitudinal and event time data using standard computer packages". The American Statistician, 58(1), 16-24.

Habyarimana, F. 2016. Measuring poverty and child malnutrition with their determinants from household survey data. PhD thesis: Univesity of KwaZulu-Natal.

Habyarimana, F., Zewotir, T. and Ramroop, S. 2014. "A Proportional Odds Model with Complex Sampling Design to Identify Key Determinants of Malnutrition of Children under Five Years in Rwanda". Mediterranean Journal of Social Sciences, 5(23), 1642-1648.

Islam, M. M., Alam, M., Tariquzaman, M., Kabir, M. A., Pervin, R., Begum, M. and Khan, M. M. H. 2013. "Predictors of the number of underfive malnourished children in Bangladesh: application of the generalized poisson regression model". BMC Public Health, 13(1), 1-8.

Kandala, N.B., Madungu, T. P., Emina, J. B., Nzita, K. P. and Cappuccio, F. P. 2011. "Malnutrition among children under the age of 
five in the Democratic Republic of Congo (DRC): does geographic location matter?". BMC Public Health, 11(1), 261-275.

Kandala, N. B., Lang, S., Klasen, S. and Fahrmeir, L. 2001. Semiparametric analysis of the socio-demographic and spatial determinants of undernutrition in two african countries. Research in official statistics, 4(1), 81-100.

Khatab, K. 2010. "Childhood malnutrition in Egypt using geoadditive Gaussian and latent variable models". The American journal of tropical medicine and hygiene, 82(4), 653663.

Matanda, D. J., Mittelmark, M. B. and Kigaru, D. M. D. 2014. "Child undernutrition in Kenya:trend analyses from 1993 to 2008-09". BMC Pediatrics, 14(1), 5.

Nguefack-Tsague, G. and Dapi, N. 2011. Multidimensional Nature of Undernutrition: A Statistical Approach.

Nguefack-Tsague, G., Kien, A. T. N. and Fokunang, C. N. 2013. "Using weight-for-age for predicting wasted children in Cameroon". Pan African Medical Journal, 14(1),1-6.

NISR, ICF and MoH. 2012. Rwanda Demographic and Health Survey 2010.

Onis, M. d. (2000). "Measuring nutritional status in relation to mortality". Bulletin of the World Health Organization, 78(10), 1271-1274.

Setboonsarng, S. 2005. Child malnutrition as a poverty indicator: An evaluation in the context of different development interventions in Indonesia: ADB Institute Discussion Papers No.21.

Skoufias, E. 1998. "Determinants of child health during the economic transition in Romania". World Development, 26(11), 2045-2056.

Takele, K. 2013. Semi-Parametric Analysis of Children Nutritional Status in Ethiopia. International Journal of Statistics and Applications, 3(5), 141-154.

Tathiah, N., Moodley, I., Mubaiwa, V., Denny, L. and Taylor, M. 2013. "South Africa's nutritional transition: Overweight, obesity, underweight and stunting in female primary school learners in rural KwaZulu-Natal, South Africa". SAMJ: South African Medical Journal, 103(10), 718-723.

Tharakan, C. T. and Suchindran, C. M. 1999. "Determinants of child malnutrition-an intervention model for Botswana". Nutrition Research, 19(6), 843-860.

Tsiatis, A. A. and Davidian, M. 2004. "Joint modeling of longitudinal and time-to-event data: an overview". Statistica Sinica, 14(3), 809-834.
UNICeF. (1998). The state of the world children's 1998: Focus on Nutrition. New York: UNICEF.

Verbeke, G. 2005. Models for Discrete Longitudinal Data. Springer Series in Statistics: Springer.

Verbeke, G., Fieuws, S., Molenberghs, G. and Davidian, M. 2014. "The analysis of multivariate longitudinal data: A review". Statistical methods in medical research, 23(1), $42-59$.

Wagstaff, A. 2004. The Millennium Development Goals for health: rising to the challenges: World Bank Publications.

Walker, I., Marini, A., Lucchetti, L., Waters, W. and Lastra, A. 2007. "Nutritional failure in Ecuador: causes consequences and solutions". International Journal of Statistitcs and

Application,3(5),141.doi:10.5923/j.stattistics.2 0130305.01

WHO. 1995. Physical Status: the Use and Interpretation of Anthropometry:Report of a WHO Expert Committee.

Zere, E. and McIntyre, D. 2003. "Inequities in under-five child malnutrition in South Africa". International Journal for Equity in Health, 2(1), 7. 